UPPSALA UNIVERSITET
Working Paper 2005:7

Department of Economics

Optimal Redistributive Taxation when Government's and Agents' Preferences Differ

Sören Blomquist and Luca Micheletto 
Department of Economics

Uppsala University

P.O. Box 513

SE-751 20 Uppsala

Sweden

Fax: +4618471 1478
Working paper 2005:7

March 2005

ISSN 0284-2904

Optimal Redistributive TaXation When

Government's And Agents' Preferences Differ

SÖREN Blomquist ANd Luca Micheletto

Papers in the Working Paper Series are published on internet in PDF formats.

Download from http://www.nek.uu.se

or from S-WoPEC http://swopec.hhs.se/uunewp/ 


\title{
Optimal Redistributive Taxation when Government's and Agents' Preferences Differ
}

\author{
Sören Blomquist*and Luca Micheletto ${ }^{\dagger}$ \\ 21 February 2005
}

\begin{abstract}

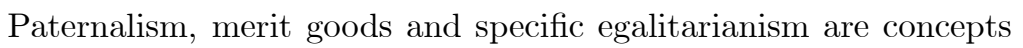
we sometimes meet in the literature. The thing in common is that the policy maker does not fully respect the consumer sovereignty principle and design policies according to some other criterion than individuals' preferences. Using the self-selection approach to tax problems developed by Stiglitz (1982) and Stern (1982), the paper provides a characterization of the properties of an optimal redistributive mixed tax scheme in the general case when the government evaluates individuals' well-being using a different utility function than the one maximized by private agents.
\end{abstract}

Keywords: optimal taxation; behavioral economics; paternalism; merit goods; non-welfarism

JEL Classification: $\mathrm{H} 21, \mathrm{H} 23$

\footnotetext{
*Uppsala University, Department of Economics, Box 513 SE-751 20 Uppsala, Sweden.

${ }^{\dagger}$ Corresponding author: Luca Micheletto, Uppsala University, Department of Economics, Box 513 SE-751 20 Uppsala, Sweden. Tel.: 00461847116 33; fax: 004618 47114 78; e-mail addresses: luca.micheletto@nek.uu.se; luca.micheletto@unibocconi.it
} 


\section{Introduction}

Paternalism, merit goods and specific egalitarianism are concepts that we now and then come across in the literature. The thing in common for these concepts is that the policy maker does not fully respect individuals' preferences but regards them as deficient in some way. The decisions made by individuals need to be corrected. Although fairly frequently mentioned in the literature, there is not much formal analysis of the implications of these ideas for policy making. Often verbal arguments have been used to derive the implications. In this paper we attempt to close this gap by providing a framework that covers all three ideas mentioned above and study the implications for income and commodity taxation. The framework we provide can also handle some other non-welfaristic approaches.

Paternalism is probably the concept with the oldest tradition going back as far as Plato's writings. The general idea is that (some) individuals do not know what is best for them. Some other person with the power to decide knows "better" what will be beneficial for the individuals, and overrules their wishes. Laws restricting the behavior of individuals are often motivated by paternalistic arguments. The concept is still much discussed among philosophers as well as economists. For example, in the 2003 May issue of American Economic Review a full session is devoted to a discussion of paternalism. Thaler and Sunstein (2003) make a strong argument for an important role for paternalism.

The concept of merit wants was introduced by Musgrave (1959). According to him (Musgrave, 1959, p.13) "Such wants are met by services subject to the exclusion principle and are satisfied by the market within the limits of effective demand. They become public wants if considered so meritorious that their satisfaction is provided for through the public budget, over and above what is provided for through the market and paid for by private buyers." It has indeed been difficult to give a strict definition in terms of properties of the policy-makers preference function. Sandmo (1983) discusses decision making in a context of uncertainty. Individuals' information on probabilities might be incorrect, whereas the policy maker has better information. According to Sandmo this might provide the underpinnings for the policy maker to use a merit good formulation of its policies. This line of reasoning resembles the ideas presented in Blomquist and Micheletto (2003). In a model of age related income taxation they argue that individuals in their decision making maximize their expected lifetime utility, whereas the policy maker is interested in the distribution of actual lifetime utilities. In their model it is true that the policy maker respects individual preferences, but it is still the case that the policy maker maximizes another function than what individuals maximize.

There have been attempts to capture the notion of a merit good in terms of properties of a direct utility function. Besley (1988) proposed a 
formulation that was meant to capture the merit good aspect in a simple way. However, as shown by Schroyen (2004), the Besley formulation is ambiguous. Schroyen (2004) and Racionero (2001) provide still other ways to try and capture the notion of a merit good in terms of a property of a direct utility function. We will consider both in the paper. Another possibility that we discuss extensively below would be to define a merit good as a good which is such that its consumption should be encouraged by the commodity tax system in some particular way.

The idea of specific egalitarianism has been presented by, for example, Tobin (1970). According to this concept the policy maker, besides having views on the distribution of income in general, has more specific egalitarian goals for one or more particular goods. According to Tobin specific egalitarianism provides an argument for public provision of the good in question. Tobin did not perform a formal analysis and it is not obvious that his claim is correct; for example, subsidies might provide an instrument as good as or better than public provision. However, we will not study this issue here.

Whatever we would like to call the phenomenon, it seems as if actual policy making often has characteristics that are hard to explain without recourse to some of the concepts mentioned above. Some examples are given by the public policies with respect to pension savings, education and the use of alcohol, narcotics and tobacco.

With respect to pension savings there is a worry that some individuals would save too little for their old age. To correct this behavior compulsory savings schemes have been introduced. Sometimes subsidies to pension savings are used. With respect to the last three goods the worry is that people would consume too much if left unrestricted. The public policy to try to cut down on the use has in some cases been via taxes, but also by forbidding (like for narcotics) or imposing physical restrictions so that only a certain amount of spirits could be bought per month. A recent phenomenon is the discussion of the role of fat and sugar for obesity. Some individuals might be addicted to fat/sugar in a way similar to how people are addicted to say tobacco or alcohol. A tax on fat and/or sugar has therefore been advocated.

We will not go into a discussion of under what conditions it is "right" to base public policies on preferences that differ from individuals' ones, we will instead focus on how optimal policies should be designed when the policy maker has another set of preferences than individuals. We recognize that such a framework might in principle imply that public provision of some private goods represents a more efficient solution than using taxes and subsidies. Nonetheless, in this paper we limit ourselves to study how optimal commodity and income taxes should be designed, leaving for future work to investigate whether public provision would be part under some circumstances of an optimal policy.

In contrast to some recent papers on merit goods we do not attempt to capture the idea of merit goods by imposing some strong structure on a 
utility function. Such formulations seem always to be connected with further restrictions than those embodied in the merit goods concept. Instead, the general assumption underlying our analysis is that the policy maker uses another function to evaluate outcomes than the one used by individuals. We only impose the condition that the policy maker's function is convex. Using this formulation we are still able to obtain sharp characterizations of commodity and income taxes. Our approach covers some of the merit good models as special cases, but is also valid for other interpretations.

The plan of the paper is as follows. Section 2 presents the general formulation of the government's problem. In Section 3 and 4 the main results on the optimal mixed tax structure are derived and discussed. Section 5 discusses three special cases. Section 6 concludes.

\section{The Model}

The model is a straightforward extension of Edwards et al. (1994) which in turn relies on the two-types version of the Mirrlees (1971) model developed by Stiglitz (1982) and Stern (1982). The economy is populated by two types of individuals differing only with respect to their (inalterable and) innate (market) ability: type 1 are low skilled agents whereas type 2 are high skilled ones. The difference in ability (output produced per unit of time spent working) is reflected in the difference in unitary wage $(w)$ the two types of agents are paid: $w^{2}>w^{1}$. Without loss of generality we assume that the population of both types of workers is the same and we normalize it to one. Agents have identical preferences described by a quasi-concave utility function $u\left(x_{1}, x_{2}, x_{3}, L\right)$, where $L$ is the labor supply whereas $x_{1}, x_{2}$ and $x_{3}$ are the consumption levels of the three commodities produced in the economy. ${ }^{1}$ Production is linear and uses labor as the only input; units are chosen to make all producer prices equal to 1 . The government knows the distribution of ability in the population but can observe neither $L$ nor $w$, while it can observe their product $Y$, earned income. Thus, the government is prevented from optimizing the income distribution imposing, as it would be first best, lump-sum taxes/transfers conditioned on ability. Instead, the government has at its disposal a general income tax $T(Y)$. The problem of choosing the direct tax schedule can be equivalently stated as the problem of selecting two pairs of pre-tax and disposable incomes $\left(Y^{k}, B^{k}\right), B^{k}=Y^{k}-$ $T\left(Y^{k}\right), k=1,2$. There is also a set of linear (more precisely, proportional) commodity taxes/subsidies: linearity follows from the assumption that the government can only observe anonymous transactions. Good 3 is chosen as

\footnotetext{
${ }^{1}$ In order to characterize the structure of indirect taxation we need a model with at least three goods: one good that is used as numéraire and with a tax rate normalized to zero, one good that can be a merit/demerit good and one good that is neither the numéraire nor the merit/demerit good. No further qualitative insights are obtained by having a model with more than three goods.
} 
numéraire and set untaxed. The design of the indirect tax structure is then reduced to the selection of the appropriate commodity taxes/subsidies $t_{1}$ and $t_{2}$ on good 1 and 2 , the consumer prices of which will be denoted by $q_{i}$ $\left(q_{i}=1+t_{i}, i=1,2\right)$.

Before presenting formally the government's problem, we need to introduce some more notation. We denote by $V\left(q_{1}, q_{2}, B, Y ; w\right)$ the conditional indirect utility obtained, for a given labor supply and for preferences described by $u(\cdot)$, by optimally allocating a fixed amount of expenditure $B$ over the consumption goods:

$$
V\left(q_{1}, q_{2}, B, Y ; w\right)=\max _{x_{1}, x_{2}, x_{3}}\left\{u\left(x_{1}, x_{2}, x_{3}, \frac{Y}{w}\right) \mid q_{1} x_{1}+q_{2} x_{2}+x_{3}=B\right\}
$$

The indirect utility is then obtained by choosing optimally labor supply in order to maximize $V\left(q_{1}, q_{2}, B, Y ; w\right)$ subject to the link between pretax earnings and post-tax earnings available for goods expenditure implied by the direct tax schedule: $B=Y-T(Y)$. Using subscripts to denote derivatives, this gives $-\frac{V_{Y}}{V_{B}}=1-\frac{\partial T(Y)}{\partial Y}$ which allows us to define implicitly the marginal income tax rate $\frac{\partial T(Y)}{\partial Y}$ faced by an agent as:

$$
\frac{\partial T(Y)}{\partial Y}=1+\frac{V_{Y}}{V_{B}}=1-M R S_{Y B}
$$

where $M R S_{Y B}$ stands for marginal rate of substitution between $Y$ and $B{ }^{2}$

\subsection{The government's problem}

We assume that for some reason the government does not respect the consumer sovereignty principle and evaluates individuals' well-being using a functional form different from $u(\cdot)$. We denote this function by $\widetilde{u}\left(x_{1}, x_{2}, x_{3}, L\right)$ and assume that it is quasi-concave. Corresponding to this direct utility function we can also define for $k=1,2$ the following indirect utility function:

$$
\begin{aligned}
\widetilde{V}^{k} & \equiv \widetilde{V}\left(q_{1}, q_{2}, B^{k}, Y^{k} ; w^{k}\right) \equiv \widetilde{u}^{k} \equiv \\
& \equiv \widetilde{u}\left(x_{1}^{k}\left(q_{1}, q_{2}, B^{k}, Y^{k} ; w^{k}\right), x_{2}^{k}\left(q_{1}, q_{2}, B^{k}, Y^{k} ; w^{k}\right), x_{3}^{k}\left(q_{1}, q_{2}, B^{k}, Y^{k} ; w^{k}\right), \frac{Y^{k}}{w^{k}}\right)
\end{aligned}
$$

where it should be stressed that the arguments in $\widetilde{u}$ are the demands generated by utility-maximizing individuals whose preferences are represented

\footnotetext{
${ }^{2}$ It is well known that with a finite group of individuals an optimal tax function is generally nondifferentiable at the points at which the schedule is actually observed. However, since the utility functions are assumed to be differentiable, even if marginal income tax rates are not well defined at an optimal allocation it is possible to define implicit (shadow) marginal tax rates using the marginal rates of substitution.
} 
by the utility function $u$. One implication of this is that we can neither invoke the envelope theorem when taking derivatives of $\widetilde{V}^{k}$ nor apply Roy's identity to the function $\widetilde{V}^{k}$.

The government's problem is to design a Pareto efficient tax policy that allows it to achieve some redistributive goals (and eventually raise some exogenous amount of revenue), given the assumed informational constraints and given that it is government's belief that individuals' preferences are "defective" in the sense specified above.

As usual, due to the non-linearity of the income tax schedule, the government must design the tax system so that each ability type (weakly) prefers the $(Y, B)$ bundle intended for it to that intended for the other (self-selection constraints). An individual that misrepresents his type is called a mimicker. Following the relevant literature, we will limit ourselves to the so called "normal" case in which the only binding self-selection constraint is the one ruling out the possibility that the high-wage households mimic the low-wage ones by earning the same income. ${ }^{3}$

Using a "hat" to characterize a variable when referred to a mimicker and defining:

$$
\begin{gathered}
V^{k}=V\left(q_{1}, q_{2}, B^{k}, Y^{k} ; w^{k}\right), \quad k=1,2, \\
\widehat{V^{2}}=V\left(q_{1}, q_{2}, B^{1}, Y^{1} ; w^{2}\right),
\end{gathered}
$$

the government's problem can be written as:

$$
\max _{Y^{1}, Y^{2}, B^{1}, B^{2}, t_{1}, t_{2}} \tilde{V}^{1}
$$

subject to:

$$
\begin{aligned}
& \widetilde{V}^{2} \geq \overline{\widetilde{V}} \\
& V^{2} \geq \widehat{V^{2}} \\
& \sum_{k=1}^{2}\left(Y^{k}-B^{k}+\sum_{i=1}^{2} t_{i} x_{i}^{k}\right) \geq \bar{R},
\end{aligned}
$$

where Lagrange multipliers are within parentheses, $\overline{\widetilde{V}}$ is a pre-set utility level, $x_{i}^{k}$ represents demand of commodity $i$ by an agent of type $k$ and $\bar{R}$ denotes the exogenous amount of revenue to be raised.

The first order conditions are:

\footnotetext{
${ }^{3}$ The "Mirrlees-Spence" single-crossing property requiring that indifference curves in the $(Y, B)$-space are shallower for high-wage households is assumed to ensure that only one self-selection constraint binds. To focus on the case when only the high-wage household is tempted to misrepresent his type, we will restrict attention solely to governments willing to redistribute from high- to low skilled agents.
} 


$$
\begin{array}{ll}
Y^{1}: & \sum_{j=1}^{3} \frac{\partial \widetilde{u}^{1}}{\partial x_{j}^{1}} \frac{\partial x_{j}^{1}}{\partial Y^{1}}+\frac{\partial \widetilde{u}^{1}}{\partial L^{1}} \frac{1}{w^{1}}=\lambda \widehat{V_{Y}^{2}}-\gamma\left(1+\sum_{j=1}^{2} t_{j} \frac{\partial x_{j}^{1}}{\partial Y^{1}}\right) ; \\
B^{1}: & \sum_{j=1}^{3} \frac{\partial \widetilde{u}^{1}}{\partial x_{j}^{1}} \frac{\partial x_{j}^{1}}{\partial B^{1}}=\lambda \widehat{V_{B}^{2}}-\gamma\left(-1+\sum_{j=1}^{2} t_{j} \frac{\partial x_{j}^{1}}{\partial B^{1}}\right) ; \\
Y^{2}: & \delta\left(\sum_{j=1}^{3} \frac{\partial \widetilde{u}^{2}}{\partial x_{j}^{2}} \frac{\partial x_{j}^{2}}{\partial Y^{2}}+\frac{\partial \widetilde{u}^{2}}{\partial L^{2}} \frac{1}{w^{2}}\right)+\lambda V_{Y}^{2}=-\gamma\left(1+\sum_{j=1}^{2} t_{j} \frac{\partial x_{j}^{2}}{\partial Y^{2}}\right) ; \\
B^{2}: & \delta \sum_{j=1}^{3} \frac{\partial \widetilde{u}^{2}}{\partial x_{j}^{2}} \frac{\partial x_{j}^{2}}{\partial B^{2}}+\lambda V_{B}^{2}=-\gamma\left(-1+\sum_{j=1}^{2} t_{j} \frac{\partial x_{j}^{2}}{\partial B^{2}}\right) ; \\
t_{i}: & \sum_{j=1}^{3} \frac{\partial \widetilde{u}^{1}}{\partial x_{j}^{1}} \frac{\partial x_{j}^{1}}{\partial q_{i}}+\delta \sum_{j=1}^{3} \frac{\partial \widetilde{u}^{2}}{\partial x_{j}^{2}} \frac{\partial x_{j}^{2}}{\partial q_{i}}+\lambda V_{q_{i}}^{2}-\lambda \widehat{V_{q_{i}}^{2}}+\gamma \sum_{k=1}^{2}\left(\sum_{j=1}^{2} t_{j} \frac{\partial x_{j}^{k}}{\partial q_{i}}+x_{i}^{k}\right)=0
\end{array}
$$

$i=1,2$.

Notice again that in deriving the first order conditions we were able to make only a limited use of the envelope theorem. In particular, we couldn't apply it when taking derivatives of $\widetilde{u}^{1}$ and $\widetilde{u}^{2}$. The reason is that there is no actual person who takes decisions maximizing $\widetilde{u}(\cdot)$ subject to a given budget constraint: the quantities $x_{i}^{1}(i=1,2,3)$ and $x_{i}^{2}(i=1,2,3)$ appearing as arguments of respectively $\widetilde{u}^{1}$ and $\widetilde{u}^{2}$ are optimal choices only from the viewpoint of agents having preferences represented by $u(\cdot)$.

\section{The Structure of Indirect Taxation}

In order to get a better grasp of the structure of the optimal commodity taxes we will represent it in several ways. Our first representation is given in Proposition 1.

Proposition 1 Denoting by $h_{i}^{k}$ the Hicksian demand for good $i$ by an agent of type $k$, the optimal commodity tax structure satisfies:

$$
\sum_{k=1}^{2} \sum_{j=1}^{2} t_{j} \frac{\partial h_{i}^{k}}{\partial q_{j}}=\underbrace{\frac{\lambda \widehat{V_{B}^{2}}}{\gamma}\left(x_{i}^{1}-\widehat{x}_{i}^{2}\right)}_{\Theta^{\prime}}-\gamma^{-1} \underbrace{\left(\sum_{j=1}^{3} \frac{\partial \widetilde{u}^{1}}{\partial x_{j}^{1}} \frac{\partial h_{j}^{1}}{\partial q_{i}}+\delta \sum_{j=1}^{3} \frac{\partial \widetilde{u}^{2}}{\partial x_{j}^{2}} \frac{\partial h_{j}^{2}}{\partial q_{i}}\right)}_{\Theta^{\prime \prime}}, i=1,2
$$

Proof. See the Appendix.

According to (6), the optimal commodity tax structure reflects a mixture of self-selection motives and difference-in-preferences considerations.

The term on the left hand side of (6) is the discouragement index (Mirrlees, 1976), an approximate measure of the change in compensated demand, 
that is of the distortions, due to the indirect tax system. For a given commodity, it is positive (negative) when the consumption of the commodity is globally encouraged (discouraged) by the indirect tax system.

The term labelled $\Theta^{\prime}$ on the right hand side of (6) is the one that one would obtain in a standard two-types model without difference in preferences between the government and private agents. It is well known from previous analyses and it pushes towards encouraging (discouraging) the consumption of a commodity complementary to labor (leisure) ${ }^{4}$ in order to relax the binding self-selection constraint. ${ }^{5}$

To provide a better understanding of the term $\Theta^{\prime \prime}$ and get an insight in how a non-uniform commodity tax structure may usefully supplement a non-linear income tax if there is a divergence between $u(\cdot)$ and $\widetilde{u}(\cdot)$, consider the following. Assume that $t_{1}=t_{2}=0$ and evaluate the effects of a small perturbation $d t_{i}$ in the consumer price of the $i$-th good accompanied by adjustments $d B^{k}=x_{i}^{k} d t_{i}$ in the disposable incomes of the two types of agents at their original (gross) earnings.

Since we have assumed to start from a situation where $t_{1}=t_{2}=0$, the proposed reform would have no effect on the revenue collected by the government from commodity taxation: $\sum_{k=1}^{2} \sum_{j=1}^{2} t_{j} \frac{\partial h_{i}^{k}}{\partial q_{j}}=0$. Moreover, as perceived by both types of agents the reform would be welfare-neutral since we have $d V^{k}=V_{q_{i}}^{k} d t_{i}+V_{B}^{k} d B^{k}=-x_{i}^{k} V_{B}^{k} d t_{i}+V_{B}^{k} x_{i}^{k} d t_{i}=0$.

However, from the policy maker's perspective the proposed reform would make a difference, even neglecting the possible effects on the binding selfselection constraint. The reason is that it would change the government's evaluation of the well-being of an agent of type $k$ by the amount

$$
\begin{aligned}
d \widetilde{u}^{k} & =\sum_{j=1}^{3} \frac{\partial \widetilde{u}^{k}}{\partial x_{j}^{k}} \frac{\partial x_{j}^{k}}{\partial q_{i}} d t_{i}+\sum_{j=1}^{3} \frac{\partial \widetilde{u}^{k}}{\partial x_{j}^{k}} \frac{\partial x_{j}^{k}}{\partial B^{k}} d B^{k} \\
& =\left[\sum_{j=1}^{3} \frac{\partial \widetilde{u}^{k}}{\partial x_{j}^{k}} \frac{\partial x_{j}^{k}}{\partial q_{i}}+x_{i}^{k} \sum_{j=1}^{3} \frac{\partial \widetilde{u}^{k}}{\partial x_{j}^{k}} \frac{\partial x_{j}^{k}}{\partial B^{k}}\right] d t_{i}=\left[\sum_{j=1}^{3} \frac{\partial \widetilde{u}^{k}}{\partial x_{j}^{k}} \frac{\partial h_{j}^{k}}{\partial q_{i}}\right] d t_{i}
\end{aligned}
$$

Thus, in assessing the costs and benefits of a revenue-neutral compensated increase in one of the commodity tax rates the policy maker has to consider also the additional effects captured by (7). The term $\Theta^{\prime \prime}$ plays exactly this role as it is immediate to recognize that the terms appearing in $\Theta^{\prime \prime}$ descend from (7) dividing $d \widetilde{u}^{k}$ by $d t_{i}$ and taking into account that in the

\footnotetext{
${ }^{4}$ In this context the expressions "complementary to labour" and "complementary to leisure" correspond respectively to the notions of "negatively related to leisure" and "negatively related to labour" as defined by Pollak (1969).

${ }^{5}$ See Edwards et al. (1994) for further details.
} 
Lagrangian of the government's problem a multiplier $\delta$ is attached to the well-being of the high skilled agents.

It is also worth noting that eq. (6) implies that the Atkinson-Stiglitz (1976) theorem breaks down in the present context. ${ }^{6}$

Another perspective of the structure of the optimal commodity tax is obtained if exploiting the symmetry of the Slutsky matrix we rewrite the left hand side of equation (6) as $\sum_{k=1}^{2} \sum_{j=1}^{2} t_{j} \frac{\partial h_{j}^{k}}{\partial q_{i}}$. We can then interpret the set of equations represented by (6) as requiring that at an optimum the gains from a marginal increase in the tax rate $t_{i}$ (right hand side of (6)) should exactly balance its marginal cost (left hand side of (6)).

We can also express the optimal commodity tax structure in terms of the marginal rate of substitution for the indirect utility function. Hence, let us define $M R S_{q_{i} B}=\left(\frac{d B}{d q_{i}}\right)_{\bar{V}}=-V_{q_{i}} / V_{B}$. This marginal rate of substitution shows how much $B$ must be increased in order to keep utility unchanged if the tax on good $i$ is increased marginally. For a "traditional" indirect utility function as defined by (1) this marginal rate of substitution also gives the Marshallian demand. For the indirect utility function defined by (3) this is however not the case. Therefore, instead of using Roy's identity to rewrite $V_{q}$, we will use the identity to rewrite the Marshallian demand for good $i$ as $M R S_{q_{i} B}$. Using the Slutsky decomposition we obtain (for $k=1,2$ ):

$$
\begin{aligned}
\sum_{j=1}^{3} \frac{\partial \widetilde{u}^{k}}{\partial x_{j}^{k}} \frac{\partial h_{j}^{k}}{\partial q_{i}} & =\sum_{j=1}^{3} \frac{\partial \widetilde{u}^{k}}{\partial x_{j}^{k}} \frac{\partial x_{j}^{k}}{\partial q_{i}}+x_{i}^{k}\left(\sum_{j=1}^{3} \frac{\partial \widetilde{u}^{k}}{\partial x_{j}^{k}} \frac{\partial x_{j}^{k}}{\partial B^{k}}\right) \\
& =\widetilde{V}_{q_{i}}^{k}+x_{i}^{k} \widetilde{V}_{B}^{k}=\left(M R S_{q_{i} B}^{k}-\widetilde{M R} S_{q_{i} B}^{k}\right) \widetilde{V}_{B}^{k}
\end{aligned}
$$

Using the identities provided by (8) we can rewrite equation (6) as:

$$
\begin{aligned}
\sum_{k=1}^{2} \sum_{j=1}^{2} t_{j} \frac{\partial h_{i}^{k}}{\partial q_{j}}= & \frac{\lambda \widehat{V_{B}^{2}}}{\gamma}\left(M R S_{q_{i} B}^{1}-\widehat{M R} S_{q_{i} B}^{2}\right)+ \\
& +\frac{\widetilde{V}_{B}^{1}}{\gamma}\left(\widetilde{M R} S_{q_{i} B}^{1}-M R S_{q_{i} B}^{1}\right)+ \\
& +\frac{\delta \widetilde{V}_{B}^{2}}{\gamma}\left(\widetilde{M R} S_{q_{i} B}^{2}-M R S_{q_{i} B}^{2}\right) .
\end{aligned}
$$

\footnotetext{
${ }^{6}$ As is well known, according to the Atkinson-Stiglitz theorem, when individuals' (homogeneous) preferences are weakly separable between leisure and other goods taken together, there is no need to employ indirect taxation in the optimum solution.
} 
So far we have not discussed how to define a merit good in the present context. We believe it is natural to define a merit good in terms of the difference between $\widetilde{M R} S_{B q_{i}}^{k}$ and $M R S_{B q_{i}}^{k}$. Hence, from the policy maker's point of view good $i$ is a merit good for a type $k$ person if $\widetilde{M R} S_{q_{i} B}^{k}>$ $M R S_{q_{i} B}^{k}$. According to the government's preferences a marginal increase in the price of the good requires a compensation (in terms of disposable income) larger than according to the individual's preferences. If $\widetilde{M R} S_{q_{i} B}^{k}>M R S_{q_{i} B}^{k}$ for both the low- and the high skill types it might be reasonable to denote the good as a global merit good.

Let us consider the case of a global merit good together with a couple of simplifying assumptions. First, suppose that the self-selection term is not binding (or that leisure is weakly separable from goods). Let us also assume that there is only one good such that $\widetilde{M R} S_{q_{i} B} \neq M R S_{q_{i} B}$. Multiply (9) by $t_{i}$ and sum over $i=1,2$. Then, if the matrix of substitution effects is strictly negative definite, the left hand side of (9) is negative and the formula implies that if we have a merit good, the good should be subsidized and if it is a demerit good it should be taxed. However, in general it is not true that a merit good should necessarily be subsidized. Whether it should be taxed or subsidized also depends on the self-selection term.

It might well be that for low values of $x_{i}(\underline{q}, B, Y ; w)$, it is the case that $\widetilde{M R} S_{q_{i} B}^{1}>M R S_{q_{i} B}^{1}$. This might for example happen for, say, consumption of gym exercises, swim passes or aerobics classes. However, above a certain threshold of consumption it might be that the evaluations of the policy maker and the individual are the same so that $\widetilde{M R} S_{B q_{i}}^{1}=M R S_{B q_{i}}^{1}$. For other goods, like alcohol or cigarettes, it might be the case that if $x_{i}$ is sufficiently small $\widetilde{M R} S_{q_{i} B}^{1}=M R S_{q_{i} B}^{1}$ whereas if $x_{i}$ is large we would have that $\widetilde{M R} S_{q_{i} B}^{1}<M R S_{q_{i} B}^{1}$. Under such circumstances it can very well happen that $\widetilde{M R} S_{q_{i} B}^{1}>M R S_{q_{i} B}^{1}$ and $\widetilde{M R} S_{q_{i} B}^{2}<M R S_{q_{i} B}^{2}$ (or the reverse); then, whether we would like to tax good $i$ or subsidize it would also depend on the relative proportion of high- and low skilled agents in the population.

\section{The Marginal Effective Tax Rates}

To save space we do not discuss the marginal income tax rates but instead focus on the marginal effective tax rates. The total tax paid at income $Y$ is $\tau(Y) \equiv T(Y)+\sum_{j=1}^{2} t_{j} x_{j}\left(q_{1}, q_{2}, Y-T(Y), Y ; w\right)$. For a differentiable tax function, the marginal effective tax rate (METR) is given by: 


$$
\tau^{\prime}(Y) \equiv T^{\prime}(Y)+\sum_{j=1}^{2} t_{j}\left[\frac{\partial x_{j}}{\partial B}\left(1-T^{\prime}\right)+\frac{\partial x_{j}}{\partial Y}\right] .
$$

The formula given in (10) applies more generally if the implicit marginal income tax rate $1+\frac{V_{Y}}{V_{B}}($ see $(2))$ is substituted for $T^{\prime}(Y)$. Thus:

$\tau^{\prime}(Y) \equiv 1+\frac{V_{Y}}{V_{B}}+\sum_{j=1}^{2} t_{j}\left[-\frac{\partial x_{j}}{\partial B} \frac{V_{Y}}{V_{B}}+\frac{\partial x_{j}}{\partial Y}\right]=\frac{V_{Y}}{V_{B}}\left(1-\sum_{j=1}^{2} t_{j} \frac{\partial x_{j}}{\partial B}\right)+1+\sum_{j=1}^{2} t_{j} \frac{\partial x_{j}}{\partial Y}$

Using this definition we obtain:

Proposition 2 The METRs for high-and low skilled agents implied by the optimal mixed tax system are respectively given by:

$$
\begin{aligned}
& \tau^{\prime 2}=\underbrace{\frac{\delta}{\gamma} \widetilde{V}_{B}^{2}\left(\widetilde{M R} S_{Y B}^{2}-M R S_{Y B}^{2}\right)}_{\Psi^{\prime}} \\
& \tau^{\prime 1}=\underbrace{\frac{\lambda \widehat{V_{B}^{2}}}{\gamma}\left(M R S_{Y B}^{1}-M \widehat{R S_{Y B}^{2}}\right)}_{\Psi^{\prime \prime}}+\underbrace{\frac{\widetilde{V}_{B}^{1}}{\gamma}\left(\widetilde{M R} S_{Y B}^{1}-M R S_{Y B}^{1}\right)}_{\Psi^{\prime \prime \prime}}
\end{aligned}
$$

Proof. See the Appendix.

According to (12) the "no distortion at the top" result is violated by the introduction of a difference between the functions $u(\cdot)$ and $\widetilde{u}(\cdot)$ into an otherwise standard optimal taxation model: even for high skilled agents the distortions brought about by income and commodity taxation do not "average out" to zero.

For these agents the sign of the global distortion depends on the relative magnitude of the minimum compensation required to induce them to (work more and) marginally increase their gross income $\left(\left.\frac{d B^{2}}{d Y^{2}}\right|_{d V^{2}=0}=M R S_{Y, B}^{2}\right)$ as compared to the minimum compensation that should accompany a marginal increase in $Y^{2}$ in order to leave unaffected their well-being when this is evaluated according to the function $\widetilde{u}(\cdot)$ (what we denote by $\widetilde{M R} S_{Y, B}^{2}$ ). If the former falls short of the latter then (12) tells us it is optimal to let high skilled agents face a positive marginal effective tax rate, inducing them to undersupply labor. A negative marginal effective tax rate, providing an incentive to oversupply labor, will instead be the optimal outcome when $M R S_{Y, B}^{2}>\widetilde{M R} S_{Y, B}^{2}$

As regards the low skilled agents, the term labelled $\Psi^{\prime \prime}$ in (13) is well known from previous research and it is due to the self-selection constraint 
faced by the government in pursuing its redistributive goals. It is positive because of the "Mirrlees-Spence" single-crossing property (see footnote 3 ). The term labelled $\Psi^{\prime \prime \prime}$ is analogous to the term $\Psi^{\prime}$ in (12) and its interpretation proceeds along the same lines. The only difference is that its sign depends on the relative magnitude of the minimum compensation required to induce low skilled agents to marginally increase their gross income $\left(\left.\frac{d B^{1}}{d Y^{1}}\right|_{d V^{1}=0}=M R S_{Y, B}^{1}\right)$ as compared to the minimum compensation needed to leave unaffected their well-being when evaluated according to the function $\widetilde{u}(\cdot)$ (what we denote by $\widetilde{M R} S_{Y, B}^{1}$ ).

\section{A Comparison with Related Models}

The general formulation of the government's problem that we presented in Section 2 covers as special cases the models considered by Racionero (2001) and Schroyen (2004) in their analyses of an economy with merit goods. Both authors want to capture the notion of a merit good by using an explicit functional form from which it can be immediately detected which good is the merit/demerit good.

\subsection{The model by Racionero (2001)}

Racionero considers a model with leisure and two goods and represents the policy maker's preferences as $\widetilde{u}\left(x_{1}, x_{2}, L\right)=u\left(x_{1}, x_{2}, L\right)+f\left(x_{2}\right)$, where $f$ is a concave monotonic function. If $f^{\prime}>0$ she denotes the good $x_{2}$ as a merit good. To exemplify Racionero mentions a good that increases individuals' health, but that individuals do not take this into account when consuming the good. The tax on good 1 is normalized to zero. Given this normalization she shows that if $x_{2}$ is a merit good, as defined by her, it should be subsidized. It is also easy to show that $x_{2}$ should be taxed if it is a demerit good $\left(f^{\prime}<0\right)$.

The model Racionero uses is, in our view, misleadingly simple. As her model only has two goods she can not study the implications of her functional form for the tax structure in general. As we will show, in a model with more than two goods, the tax/subsidy on goods other than the merit good are also affected by the difference in preferences between the individual and the policy maker. Also, her definition of the merit good is hard to generalize to a setting with more than two goods. We believe the indirect utility function is better suited to define what a merit good is. In the context of Racionero's model, with only two goods, her definition and ours are consistent, but our definition also applies to a context with many goods.

Below we will study the implications of the functional form used by Racionero, but, in order to be able to say something about the tax structure in general, we consider a model with three goods. That is, we will as- 
sume the individuals' preferences are represented by a direct utility function $u\left(x_{1}, x_{2}, x_{3}, L\right)$ and the policy maker's utility function by $\widetilde{u}\left(x_{1}, x_{2}, x_{3}, L\right)=$ $u\left(x_{1}, x_{2}, x_{3}, L\right)+f\left(x_{2}\right)$. It is obvious that given this functional form both $\widetilde{M R} S_{q_{1} B}$ and $\widetilde{M R} S_{q_{2} B}$ differ from the individuals' $M R S_{q B}$ implying that there is a contribution to the tax/subsidy on both good 1 and good 2 from the difference in preferences between the individual and the policy maker.

In order to characterize the structure of indirect taxation it is useful to note that the following relations hold for $k=1,2$ :

$$
\sum_{j=1}^{3} \frac{\partial \widetilde{u}^{k}}{\partial x_{j}^{k}} \frac{\partial h_{j}^{k}}{\partial q_{i}}=\sum_{j=1}^{3} \frac{\partial u^{k}}{\partial x_{j}^{k}} \frac{\partial h_{j}^{k}}{\partial q_{i}}+f^{\prime}\left(x_{2}^{k}\right) \frac{\partial h_{2}^{k}}{\partial t_{i}}=f^{\prime}\left(x_{2}^{k}\right) \frac{\partial h_{2}^{k}}{\partial t_{i}},
$$

since $\sum_{j=1}^{3} \frac{\partial u^{k}}{\partial x_{j}^{k}} \frac{\partial h_{j}^{k}}{\partial q_{i}}=0$. This implies that we can in this case rewrite eq. (6) as:

$$
\sum_{k=1}^{2} \sum_{j=1}^{2} t_{j} \frac{\partial h_{i}^{k}}{\partial t_{j}}=\frac{\lambda \widehat{V_{B}^{2}}}{\gamma}\left(x_{i}^{1}-\widehat{x_{i}^{2}}\right) \underbrace{-\frac{1}{\gamma}\left[f^{\prime}\left(x_{2}^{1}\right) \frac{\partial h_{2}^{1}}{\partial t_{i}}+\delta f^{\prime}\left(x_{2}^{2}\right) \frac{\partial h_{2}^{2}}{\partial t_{i}}\right]}_{\Phi}, \quad i=1,2
$$

For the case of $f$ monotonically increasing the term labelled $\Phi$ in (14) pushes towards encouraging the consumption of the (merit) good 2 and discouraging (encouraging) the consumption of the commodities that are Hicksian substitutes (complements) for the (merit) good 2. On the other hand, if $f$ were monotonically decreasing, the term $\Phi$ would discourage the consumption of the (demerit) good 2 and encourage (discourage) the consumption of the commodities that are Hicksian substitutes (complements) for the (demerit) $\operatorname{good} 2$.

Further, defining $J=\sum_{k=1}^{2} \frac{\partial h_{1}^{k}}{\partial t_{1}} \sum_{k=1}^{2} \frac{\partial h_{2}^{k}}{\partial t_{2}}-\sum_{k=1}^{2} \frac{\partial h_{2}^{k}}{\partial t_{1}} \sum_{k=1}^{2} \frac{\partial h_{1}^{k}}{\partial t_{2}} \quad(>0)$, we can write the set of equations represented by (14) as:

$$
\begin{aligned}
t_{1}= & \frac{1}{J} \frac{\lambda}{\gamma} \widehat{V_{B}^{2}}\left(x_{1}^{1}-\widehat{x_{1}^{2}}\right)\left(\sum_{k=1}^{2} \frac{\partial h_{2}^{k}}{\partial t_{2}}\right) \\
& -\frac{1}{J} \frac{\lambda}{\gamma} \widehat{V_{B}^{2}}\left(x_{2}^{1}-\widehat{x_{2}^{2}}\right)\left(\sum_{k=1}^{2} \frac{\partial h_{2}^{k}}{\partial t_{1}}\right) \\
& -\frac{1}{J} \gamma^{-1}\left(f^{\prime}\left(x_{2}^{1}\right) \frac{\partial h_{2}^{1}}{\partial t_{1}}+\delta f^{\prime}\left(x_{2}^{2}\right) \frac{\partial h_{2}^{2}}{\partial t_{1}}\right)\left(\sum_{k=1}^{2} \frac{\partial h_{2}^{k}}{\partial t_{2}}\right)+
\end{aligned}
$$




$$
\begin{aligned}
+\frac{1}{J} \gamma^{-1}\left(f^{\prime}\left(x_{2}^{1}\right) \frac{\partial h_{2}^{1}}{\partial t_{2}}+\delta f^{\prime}\left(x_{2}^{2}\right) \frac{\partial h_{2}^{2}}{\partial t_{2}}\right)\left(\sum_{k=1}^{2} \frac{\partial h_{2}^{k}}{\partial t_{1}}\right), \\
t_{2}=\frac{1}{J} \frac{\lambda}{\gamma} \widehat{V_{B}^{2}}\left(x_{2}^{1}-\widehat{x_{2}^{2}}\right)\left(\sum_{k=1}^{2} \frac{\partial h_{1}^{k}}{\partial t_{1}}\right) \\
+\frac{1}{J} \frac{\lambda}{\gamma} \widehat{V_{B}^{2}}\left(\widehat{x_{1}^{2}}-x_{1}^{1}\right)\left(\sum_{k=1}^{2} \frac{\partial h_{1}^{k}}{\partial t_{2}}\right) \\
-\frac{1}{J} \gamma^{-1}\left(f^{\prime}\left(x_{2}^{1}\right) \frac{\partial h_{2}^{1}}{\partial t_{2}}+\delta f^{\prime}\left(x_{2}^{2}\right) \frac{\partial h_{2}^{2}}{\partial t_{2}}\right)\left(\sum_{k=1}^{2} \frac{\partial h_{1}^{k}}{\partial t_{1}}\right) \\
+\frac{1}{J} \gamma^{-1}\left(f^{\prime}\left(x_{2}^{1}\right) \frac{\partial h_{2}^{1}}{\partial t_{1}}+\delta f^{\prime}\left(x_{2}^{2}\right) \frac{\partial h_{2}^{2}}{\partial t_{1}}\right)\left(\sum_{k=1}^{2} \frac{\partial h_{1}^{k}}{\partial t_{2}}\right),
\end{aligned}
$$

From this we see that, although the functional form assumption to characterize the merit good is intuitively appealing, the fact that there is a difference in preferences between the individuals and the policy maker does not only affect the structure of the optimal commodity tax rate on good 2, but it also affects the structure (and not merely the values) of the commodity tax rates on the remaining (non-target) goods. In fact it is possible that good 1 should be subsidized to a larger extent than good 2. This illustrates, that the Racionero definition of a merit good makes little sense in a context with more than two goods.

Only under further strong assumptions we would obtain the result that only the tax on the "merit" good is affected by the difference in preferences between individuals and the policy maker. The condition that makes the contribution from the difference in preferences to the tax/subsidy on good 1 equal to zero is the following:

$$
\frac{f^{\prime}\left(x_{2}^{1}\right) \frac{\partial h_{2}^{1}}{\partial t_{2}}+\delta f^{\prime}\left(x_{2}^{2}\right) \frac{\partial h_{2}^{2}}{\partial t_{2}}}{\sum_{k=1}^{2} \frac{\partial h_{2}^{k}}{\partial t_{2}}}=\frac{f^{\prime}\left(x_{2}^{1}\right) \frac{\partial h_{2}^{1}}{\partial t_{1}}+\delta f^{\prime}\left(x_{2}^{2}\right) \frac{\partial h_{2}^{2}}{\partial t_{1}}}{\sum_{k=1}^{2} \frac{\partial h_{2}^{k}}{\partial t_{1}}}
$$

That is, the sum of the policy maker's marginal valuations of the "merit" good, weighted by (compensated) quantity response to direct price change $\left(t_{2}\right)$, be equal to the sum of policy maker's marginal valuations of the "merit" good, weighted by (compensated) quantity response to indirect price change $\left(t_{1}\right)$. In a model with many goods the generalization of condition (15) would be very restrictive.

To see how our expressions (12) and (13) for the METRs reduce to in the special case dealt with by Racionero, notice first that $\forall k \in\{1,2\}$ we have: 


$$
\begin{aligned}
\widetilde{V}_{B}^{k}\left(\widetilde{M R} S_{Y B}^{2}-M R S_{Y B}^{2}\right) & =-f^{\prime}\left(x_{2}^{k}\right) \frac{\partial x_{2}^{k}}{\partial Y^{k}}+\frac{V_{Y}^{k}}{V_{B}^{k}} f^{\prime}\left(x_{2}^{k}\right) \frac{\partial x_{2}^{k}}{\partial B^{k}} \\
& =-\left.f^{\prime}\left(x_{2}^{k}\right) \frac{d x_{2}^{k}}{d Y^{k}}\right|_{d V^{k}=0},
\end{aligned}
$$

where we use $\left.\frac{d x}{d Y}\right|_{d V=0}$ to denote $\frac{\partial x}{\partial Y}-\frac{V_{Y}}{V_{B}} \frac{\partial x_{2}^{k}}{\partial B^{k}}$, i.e. the marginal effect of an increase in $Y$ that is compensated by an increase in $B$ so as to keep utility constant. Moreover, since $\left.\frac{d u^{k}}{d Y^{k}}\right|_{d V^{k}=0}=0$, we have also:

$$
\left.\frac{d \widetilde{u}^{k}}{d Y^{k}}\right|_{d V^{k}=0}=\left.\frac{d u^{k}}{d Y^{k}}\right|_{d V^{k}=0}+\left.f^{\prime}\left(x_{2}^{k}\right) \frac{d x_{2}^{k}}{d Y^{k}}\right|_{d V^{k}=0}=\left.f^{\prime}\left(x_{2}^{k}\right) \frac{d x_{2}^{k}}{d Y^{k}}\right|_{d V^{k}=0}
$$

Under the functional form assumptions used by Racionero the METRs can therefore be written as: ${ }^{7}$

$$
\begin{gathered}
\tau^{\prime 2}=-\left.\frac{\delta}{\gamma} f^{\prime}\left(x_{2}^{2}\right) \frac{d x_{2}^{2}}{d Y^{2}}\right|_{d V^{2}=0} ; \\
\tau^{\prime 1}=\frac{\lambda \widehat{V_{B}^{2}}}{\gamma}\left(M R S_{Y, B}^{1}-M \widehat{R S_{Y, B}^{2}}\right)-\left.\gamma^{-1} f^{\prime}\left(x_{2}^{1}\right) \frac{d x_{2}^{1}}{d Y^{1}}\right|_{d V^{1}=0} .
\end{gathered}
$$

In (16) and (17) the sign of $\left.\frac{d x_{2}^{k}}{d Y^{k}}\right|_{d V^{k}=0}$ depends on the relationship of Hicksian complementarity or Hicksian substitutability between commodity 2 and leisure. In particular, if good 2 and leisure are Hicksian complements (substitutes), then $\left.\frac{d x_{2}^{k}}{d Y^{k}}\right|_{d V^{k}=0}<(>) 0$. Thus, according to (16) we have that the sign of $\tau^{\prime 2}$ is the opposite of the sign of the product $\left.f^{\prime}\left(x_{2}^{2}\right) \frac{d x_{2}^{2}}{d Y^{2}}\right|_{d V^{2}=0}$ : if $f$ is a monotonically increasing function (the case of 2 being a merit good in Racionero's model) the government will induce high skilled agents to underprovide (over-provide) labor if leisure and good 2 are Hicksian complements (substitutes). The reverse holds if $f$ is a monotonically decreasing function (what would represent the case of 2 being a demerit good in Racionero's model). Similar considerations apply for the METR faced by low skilled agents with respect to the second term on the right hand side of (17).

\footnotetext{
${ }^{7}$ The expressions provided by Racionero for the METRs faced by different agents take a slightly different form from ours due to the fact that in solving the optimal taxation problem she follows an alternative approach (the one used by Nava, Schroyen and Marchand (1996)), linearizing for each individual the income tax schedule around the equilibrium points and defining in this way two virtual budget constraints, one for each type of individual.
} 


\subsection{The model by Schroyen (2004)}

Like Racionero, Schroyen tries to capture the concept of a merit good by a special functional structure of the policy maker's utility function. In the Schroyen model there are three goods (and no leisure). Schroyen introduces a total willingness to pay function in terms of the numéraire commodity. This function, denoted by $F\left(x_{1}, x_{2}, U\right)$ gives the amount of good 3 (the numéraire) required to bring an individual with preferences represented by $u(\cdot)$ to the utility level $U$ when consuming $x_{1}$ and $x_{2}$ of the nonnuméraire commodities. For someone (the policy maker) with preferences represented by $\widetilde{u}(\cdot)$ the corresponding function is denoted by $\widetilde{F}\left(x_{1}, x_{2}, U\right)$. The function $\mu\left(x_{2}\right)=\frac{\partial F\left(x_{1}, x_{2}, U\right)}{\partial x_{2}}-\frac{\partial \widetilde{F}\left(x_{1}, x_{2}, U\right)}{\partial x_{2}}$ measures the difference between the individual and the policy maker in the marginal willingness to pay for good 2. According to Schroyen's definition good 2 is a merit (demerit) good when $\mu(\cdot)>(<) 0$. Finally, Schroyen assumes that there exists a threshold level $\underline{x}_{2}$ above which the marginal evaluation of good 2 for someone with preferences represented by $\widetilde{u}(\cdot)$ starts to deviate from that of someone with preferences represented by $u(\cdot)$. Together, these assumptions implies that the policy maker's utility function can be written as $\tilde{u}\left(x_{1}, x_{2}, x_{3}\right)=u\left(x_{1}, x_{2}, x_{3}+\int_{\underline{x}_{2}}^{x_{2}} \mu(\chi) d \chi\right)$.

The tax on the numéraire good $\left(x_{3}\right)$ is normalized to zero. Schroyen's informational assumptions differ from ours (implying a difference in the set of tax instruments the policy maker can use). He characterizes first and second best commodity taxes, but not the case with self-selection constraints. He finds that both non-numéraire goods should be subsidized. Hence, if the intuition is that the merit good is the only commodity that ought to be subsidized, this is not captured by Schroyen's model. In a sense Schroyen's model seems to be more restrictive than the Racionero's model since the former implies that good one, which is not the merit good, should be subsidized. In Racionero's model extended to three goods the non-numéraire non-merit good $x_{1}$ should be taxed or subsidized depending on the exact properties of the individuals' utility functions.

Schroyen does not have leisure in his model. However, it is easy to adapt the Schroyen framework to the case where leisure is also an argument in the utility function. The individuals' preferences would be represented by $u\left(x_{1}, x_{2}, x_{3}, L\right)$ whereas the policy maker's evaluation would be according to $\tilde{u}\left(x_{1}, x_{2}, x_{3}, L\right)=u\left(x_{1}, x_{2}, x_{3}+\int_{\underline{x}_{2}}^{x_{2}} \mu(\chi) d \chi, L\right)$. It is straightforward to apply our formulas for the indirect taxes and the METRs to this particular utility function. In order to save space we do not pursue this exercise here. 


\subsection{Minimizing poverty: The problem by Kanbur, Keen and Tuomala (1994)}

Another case that can be analyzed using the framework of Section 2 is the one of a policy maker concerned with the non-welfaristic objective of the minimization of poverty. It has been claimed (see e.g. Kanbur, Keen and Tuomala, 1994) that while conventional optimal tax literature takes into account the values of both disposable income and leisure in assessing individuals' well-being, the policy discussion focuses almost exclusively on incomes. This is just another example of situations when alternatives are evaluated by a policy maker referring to something other than individuals' perceptions of their own well-being. The problem of alleviating income-poverty has been considered by Kanbur, Keen and Tuomala (1994) in a setting with a continuum of ability types and where the government's objective was the minimization of some income-based poverty index. Here we adapt the model we presented in Section 2 to restate that problem in a simpler way that allows to derive more clearcut results. For this, consider the case of individuals having preferences represented by the additive separable utility function $U=u\left(x_{1}, x_{2}, x_{3}\right)-f(L)$. Using our notation, a setting where the government is concerned with minimizing poverty (which amounts to max $\left.B^{1}\right)$ can be represented by letting $\widetilde{u}\left(x_{1}, x_{2}, x_{3}, L\right)=u\left(x_{1}, x_{2}, x_{3}\right)$. In such a case we would get the following results.

Since labor is separable from other goods in the individuals' utility function, the self-selection term $\Theta^{\prime}$ in (6) cancels out; moreover, since the policy maker "respects" the individuals' tastes when considering goods other than leisure, the term $\Theta^{\prime \prime}$ also goes to zero. Commodity taxation would therefore turn out to be redundant: $t_{i}=0, i=1,2,3$.

Since the policy maker makes only use of income taxation, the optimal marginal effective tax rates provided by (12) and (13) represent in this case optimal marginal income tax rates. These are respectively given by:

$$
\begin{aligned}
\tau^{\prime 2}= & T^{\prime 2}=\frac{\delta}{\gamma} \widetilde{V}_{B^{2}}^{2}\left(\widetilde{M R} S_{Y, B}^{2}-M R S_{Y, B}^{2}\right) \\
\tau^{\prime 1}= & T^{\prime 1}=\frac{\lambda \widehat{V}_{B}^{2}}{\gamma}\left(M R S_{Y, B}^{1}-M \widehat{R S_{Y, B}^{2}}\right)+ \\
& +\frac{\widetilde{V}_{B^{1}}^{1}}{\gamma}\left(\widetilde{M R} S_{Y, B}^{1}-M R S_{Y, B}^{1}\right) .
\end{aligned}
$$

Moreover, given that the government is completely disregarding the utility related to the availability of leisure time and taking into account

that for this particular specification of the utility functions $\widetilde{V}_{B^{1}}^{1}=V_{B^{1}}^{1}$ and $\widetilde{V}_{B^{2}}^{2}=V_{B^{2}}^{2}$, (18) and (19) take a very simple form reducing to: 


$$
\begin{aligned}
\tau^{\prime 2} & =T^{2}=-\frac{\delta}{\gamma} \widetilde{V}_{B^{2}}^{2} M R S_{Y, B}^{2}=-\frac{\delta}{\gamma} V_{B^{2}}^{2} M R S_{Y, B}^{2}<0 \\
\tau^{\prime 1} & =T^{\prime 1}=\frac{\lambda \widehat{V_{B}^{2}}}{\gamma}\left(M R S_{Y, B}^{1}-M \widehat{R S_{Y, B}^{2}}\right)-\frac{\widetilde{V}_{B^{1}}^{1}}{\gamma} M R S_{Y, B}^{1} \\
& =\frac{\lambda \widehat{V_{B}^{2}}}{\gamma}\left(M R S_{Y, B}^{1}-M \widehat{R S_{Y, B}^{2}}\right)-\frac{V_{B^{1}}^{1}}{\gamma} M R S_{Y, B}^{1} .
\end{aligned}
$$

If the policy maker wished instead to maximize the disposable income of the low skilled subject to a set of constraints including $U^{2} \geq \bar{U}$ rather than $B^{2} \geq \overline{B^{2}}$ as we implicitly assumed so far, then commodity taxation would still be redundant and the optimal METRs faced by low skilled agents would still be given by (20). The only difference would regard the optimal distortion imposed on the high ability type for whom the no distortion at the top result $\left(\tau^{\prime 2}=T^{\prime 2}=0\right)$ would be recovered.

\section{Summary and Concluding Remarks}

Recently there have been several attempts of formalizing the idea of merit goods and study the implications for commodity and income taxation. These attempts have often started with postulating a particular structure on the policy maker's "utility" function in a way such that the policy maker's utility function is a fairly simple transformation of the individuals' utility functions. Usually this approach have run into problems. In this paper we take a broader approach, not imposing other restrictions on the policy maker's utility function than that it should be convex. This approach covers some of the earlier formulations as special cases, but can also represent cases that we maybe would not like to call merit good situations.

Using the two-types two-goods version of the optimal taxation problem we have explored the consequences for the structure of direct and indirect taxation of a divergence between the individuals' and the policy maker's utility functions. We have shown that the general structure of the solution is rather simple. Typically, the tax/subsidy on a good depends on two types of terms. First, the usual terms reflecting the effect of the commodity taxes on the self-selection constraint still play a role similar to the one in the standard model. Second, there are terms reflecting the difference between an individual and the policy maker in the evaluation of goods. We have used several equivalent ways to characterize the optimal structure of indirect taxes. In one characterization we use the marginal rate of substitution between the tax on a good and the after tax income $\left(M R S_{q_{i} B}\right)$. In this characterization the self-selection term is proportional to the difference in 
the marginal rates of substitution between the low ability person and the mimicker. The terms that reflect that individuals and the policy maker have different preferences are proportional to the difference in the marginal rates of substitution between an individual and the policy maker.

We have also characterized the marginal effective tax rates (METRs). As compared with a standard model of optimal income and commodity taxes there are now new terms in the expressions for the METRs for both the high- and low skilled agents. These terms reflect the difference in $M R S_{Y B}$ between the individuals and the policy maker. An implication of this is that the METR for the high skilled is different from zero.

Although our study has not focused on how to define a merit good we believe our analysis can contribute to a better understanding of the merit good concept. Our understanding of the merit good idea is that in the view of the policy maker individuals under-consume the merit good. To stimulate the consumption of the merit good it should be subsidized. In the past various authors have suggested specific functional forms of the policy maker's direct utility function to capture the notion of a merit good. None of these suggestions have been successful. As shown by Schroyen, the Besley suggestion had the implication that the merit good should be taxed. Neither the Racionero nor the Schroyen suggestions implies that it necessarily is the merit good that should be more subsidized than other goods. Although very specialized and in some respects restrictive functional forms have been suggested, they have not been able to capture the basic intuition about merit goods. Our conclusion is that it is hard to formulate a model where only the tax/subsidy on one good is affected by the difference in preferences between individuals and the policy maker. If one wants to use the merit goods terminology we suggest a definition using the marginal rate of substitution between a tax on a good and after tax income. In general, if there is a difference in preferences between individuals and the policy maker, there would be several merit or demerit goods.

\section{Appendix}

To get the results stated in Proposition 1 and 2 it is convenient to rewrite the first order conditions of the government's problem as follows:

$$
\begin{aligned}
V_{Y}^{1} & =\lambda \widehat{V_{Y}^{2}}-\gamma\left(1+\sum_{j=1}^{2} t_{j} \frac{\partial x_{j}^{1}}{\partial Y^{1}}\right)+\xi_{Y}^{1} \\
V_{B}^{1} & =\lambda \widehat{V_{B}^{2}}-\gamma\left(-1+\sum_{j=1}^{2} t_{j} \frac{\partial x_{j}^{1}}{\partial B^{1}}\right)+\xi_{B}^{1}
\end{aligned}
$$




$$
\begin{gathered}
(\delta+\lambda) V_{Y}^{2}=-\gamma\left(1+\sum_{j=1}^{2} t_{j} \frac{\partial x_{j}^{2}}{\partial Y^{2}}\right)+\xi_{Y}^{2} \\
(\delta+\lambda) V_{B}^{2}=-\gamma\left(-1+\sum_{j=1}^{2} t_{j} \frac{\partial x_{j}^{2}}{\partial B^{2}}\right)+\xi_{B}^{2} \\
V_{q_{i}}^{1}+(\delta+\lambda) V_{q_{i}}^{2}-\lambda \widehat{V_{q_{i}}^{2}}+\gamma\left[\sum_{k=1}^{2}\left(\sum_{j=1}^{2} t_{j} \frac{\partial x_{j}^{k}}{\partial q_{i}}+x_{i}^{k}\right)\right]=-\xi_{q_{i}}
\end{gathered}
$$

where $\xi_{Y}^{1}=-\widetilde{V}_{Y}^{1}+V_{Y}^{1}, \xi_{B}^{1}=-\widetilde{V}_{B}^{1}+V_{B}^{1}, \xi_{Y}^{2}=-\delta\left(\widetilde{V}_{Y}^{2}-V_{Y}^{2}\right), \xi_{B}^{2}=$ $-\delta\left(\widetilde{V}_{B}^{2}-V_{B}^{2}\right)$ and $\xi_{q_{i}}=\widetilde{V}_{q_{i}}^{1}-V_{q_{i}}^{1}+\delta\left(\widetilde{V}_{q_{i}}^{2}-V_{q_{i}}^{2}\right)$.

Moreover, using Roy's identity and Slutsky equation, (25) becomes:

$$
\begin{aligned}
& -x_{i}^{1} V_{B}^{1}-(\delta+\lambda) x_{i}^{2} V_{B}^{2}+\lambda \widehat{x_{i}^{2}} \widehat{V_{B}^{2}}+\gamma\left[\sum_{k=1}^{2}\left(\sum_{j=1}^{2} t_{j} \frac{\partial h_{j}^{k}}{\partial q_{i}}-\sum_{j=1}^{2} t_{j} x_{i}^{k} \frac{\partial x_{j}^{k}}{\partial B^{k}}+x_{i}^{k}\right)\right] \\
= & -\widetilde{V}_{q_{i}}^{1}+V_{q_{i}}^{1}-\delta\left(\widetilde{V}_{q_{i}}^{2}-V_{q_{i}}^{2}\right) .
\end{aligned}
$$

\subsection{Proof of Proposition 1}

Multiply both sides of (22) by $-x_{i}^{1}$ and both sides of (24) by $-x_{i}^{2}$ and then substitute the expressions for $-x_{i}^{1} V_{B}^{1}$ and $-(\delta+\lambda) x_{i}^{2} V_{B}^{2}$ thus obtained in (26). This gives:

$$
\begin{array}{ll} 
& -\lambda \widehat{V_{B}^{2}} x_{i}^{1}+\gamma\left(-x_{i}^{1}+\sum_{j=1}^{2} t_{j} x_{i}^{1} \frac{\partial x_{j}^{1}}{\partial B^{1}}\right)-\xi_{B}^{1} x_{i}^{1}+\gamma\left(-x_{i}^{2}+\sum_{j=1}^{2} t_{j} x_{i}^{2} \frac{\partial x_{j}^{2}}{\partial B^{2}}\right) \\
= & -\xi_{B}^{2} x_{i}^{2}+\lambda \widehat{x_{i}^{2}} \widehat{V_{B}^{2}} \\
& -\gamma\left[\sum_{k=1}^{2}\left(\sum_{j=1}^{2} t_{j} \frac{\partial h_{j}^{k}}{\partial q_{i}}-\sum_{j=1}^{2} t_{j} x_{i}^{k} \frac{\partial x_{j}^{k}}{\partial B^{k}}+x_{i}^{k}\right)\right]-\widetilde{V}_{q_{i}}^{1}+V_{q_{i}}^{1}-\delta\left(\widetilde{V}_{q_{i}}^{2}-V_{q_{i}}^{2}\right) .
\end{array}
$$

To derive (6) substitute in (27) what $\xi_{B}^{1}$ and $\xi_{B}^{2}$ stand for, and then simplify and collect terms. 


\subsection{Proof of Proposition 2}

For the high skilled agents, first divide (23) by (24) and multiply by

$$
\begin{aligned}
& -\gamma\left(-1+\sum_{j=1}^{2} t_{j} \frac{\partial x_{j}^{2}}{\partial B^{2}}\right)+\xi_{B}^{2} . \text { It gives: } \\
& \quad \frac{V_{Y}^{2}}{V_{B}^{2}}\left[-\gamma\left(-1+\sum_{j=1}^{2} t_{j} \frac{\partial x_{j}^{2}}{\partial B^{2}}\right)+\xi_{B}^{2}\right]=-\gamma\left(1+\sum_{j=1}^{2} t_{j} \frac{\partial x_{j}^{2}}{\partial Y^{2}}\right)+\xi_{Y}^{2} .
\end{aligned}
$$

Dividing by $\gamma$, substituting in (28) what $\xi_{B}^{2}$ and $\xi_{Y}^{2}$ stand for, and rearranging terms, one gets:

$$
1+\frac{V_{Y}^{2}}{V_{B}^{2}}=\frac{\delta}{\gamma}\left(V_{Y}^{2}-\widetilde{V}_{Y}^{2}\right)-\frac{\delta}{\gamma} \frac{V_{Y}^{2}}{V_{B}^{2}}\left(V_{B}^{2}-\widetilde{V}_{B}^{2}\right)-\sum_{j=1}^{2} t_{j} \frac{\partial x_{j}^{2}}{\partial Y^{2}}+\sum_{j=1}^{2} t_{j} \frac{\partial x_{j}^{2}}{\partial B^{2}} \frac{V_{Y}^{2}}{V_{B}^{2}} .
$$

Rearranging again gives:

$$
\frac{V_{Y}^{2}}{V_{B}^{2}}\left(1-\sum_{j=1}^{2} t_{j} \frac{\partial x_{j}^{2}}{\partial B^{2}}\right)+1+\sum_{j=1}^{2} t_{j} \frac{\partial x_{j}^{2}}{\partial Y^{2}}=\frac{\delta}{\gamma}\left(V_{Y}^{2}-\widetilde{V}_{Y}^{2}\right)-\frac{\delta}{\gamma} \frac{V_{Y}^{2}}{V_{B}^{2}}\left(V_{B}^{2}-\widetilde{V}_{B}^{2}\right)
$$

(12) follows from the above equation and the definition of the METR provided by (11) after having simplified terms on the right-hand side of (30).

Proceeding similarly for the low skilled agents, divide (21) by (22) and multiply by $\lambda \widehat{V_{B}^{2}}-\gamma\left(-1+\sum_{j=1}^{2} t_{j} \frac{\partial x_{j}^{1}}{\partial B^{1}}\right)+\xi_{B}^{1}$. It gives:

$$
\frac{V_{Y}^{1}}{V_{B}^{1}}\left[\lambda \widehat{V_{B}^{2}}-\gamma\left(-1+\sum_{j=1}^{2} t_{j} \frac{\partial x_{j}^{1}}{\partial B^{1}}\right)+\xi_{B}^{1}\right]=\lambda \widehat{V_{Y}^{2}}-\gamma\left(1+\sum_{j=1}^{2} t_{j} \frac{\partial x_{j}^{1}}{\partial Y^{1}}\right)+\xi_{Y}^{1} .
$$

Dividing by $\gamma$, substituting in (31) what $\xi_{B}^{1}$ and $\xi_{Y}^{1}$ stand for, and rearranging terms, one gets:

$$
\begin{aligned}
1+\frac{V_{Y}^{1}}{V_{B}^{1}}= & \frac{\lambda \widehat{V_{Y}^{2}}}{\gamma}-\sum_{j=1}^{2} t_{j} \frac{\partial x_{j}^{1}}{\partial Y^{1}}-\frac{V_{Y}^{1}}{V_{B}^{1}} \frac{\lambda \widehat{V_{B}^{2}}}{\gamma}+\frac{V_{Y}^{1}}{V_{B}^{1}}\left(\sum_{j=1}^{2} t_{j} \frac{\partial x_{j}^{1}}{\partial B^{1}}\right)-\frac{1}{\gamma} \frac{V_{Y}^{1}}{V_{B}^{1}}\left(-\widetilde{V}_{B}^{1}+V_{B}^{1}\right) \\
& +\frac{1}{\gamma}\left(V_{Y}^{1}-\widetilde{V}_{Y}^{1}\right) .
\end{aligned}
$$

Rearranging again gives: 


$$
\begin{aligned}
\frac{V_{Y}^{1}}{V_{B}^{1}}\left(1-\sum_{j=1}^{2} t_{j} \frac{\partial x_{j}^{1}}{\partial B^{1}}\right)+1+\sum_{j=1}^{2} t_{j} \frac{\partial x_{j}^{1}}{\partial Y^{1}}= & \frac{\lambda \widehat{V_{Y}^{2}}}{\gamma}-\frac{V_{Y}^{1}}{V_{B}^{1}} \frac{\lambda \widehat{V_{B}^{2}}}{\gamma}-\frac{1}{\gamma} \frac{V_{Y}^{1}}{V_{B}^{1}}\left(-\widetilde{V}_{B}^{1}+V_{B}^{1}\right) \\
& +\frac{1}{\gamma}\left(V_{Y}^{1}-\widetilde{V}_{Y}^{1}\right) .
\end{aligned}
$$

(13) follows simplifying and collecting terms on the right-hand side of (32) and noticing that the left-hand side of (32) is precisely the definition of the METR provided by (11).

\section{References}

[1] Atkinson, A. B., and J. E. Stiglitz (1976), The Design of Tax Structure: Direct versus Indirect Taxation, Journal of Public Economics 6, 55-75.

[2] Besley, T. (1988), A Simple Model for Merit Good Arguments, Journal of Public Economics 35, 371-383.

[3] Blomquist, S., and L. Micheletto (2003), Age Related Optimal Income Taxation, Working Paper No. 2003:7, Department of Economics, University of Uppsala (also downloadable at the web site http://www.nek.uu.se/pdf/wp2003_7.pdf).

[4] Edwards, J., M. Keen and M. Tuomala (1994), Income Tax, Commodity Taxes and Public Good Provision: A Brief Guide, FinanzArchiv 51, 472-487.

[5] Kanbur, R., M. Keen and M. Tuomala (1994), Optimal Non-Linear Income Taxation for the Alleviation of Income Poverty, European Economic Review 38, 1613-1632.

[6] Mirrlees, J. (1971), An Exploration in the Theory of Optimum Income Taxation, Review of Economic Studies 38, 175-208.

[7] Mirrlees, J. (1976), Optimal Tax Theory: A Synthesis, Journal of Public Economics 6, 327-358.

[8] Musgrave, R. A. (1959), The Theory of Public Finance, New York: McGraw-Hill.

[9] Nava, M., F. Schroyen and M. Marchand (1996), Optimal Fiscal and Public Expenditure Policy in a Two-Class Economy, Journal of Public Economics 61, 119-137. 
[10] Pollak, R. A. (1969), Conditional Demand Functions and Consumption Theory, Quarterly Journal of Economics 83, 60-78.

[11] Racionero, M. Del Mar (2001), Optimal Tax Mix with Merit Goods, Oxford Economic Papers 53, 628-641.

[12] Sandmo, A. (1983), Ex Post Welfare Economics and the Theory of Merit Goods, Economica 50, 19-33.

[13] Schroyen, F. (2004), An Alternative Way to Model Merit Good Arguments, Journal of Public Economics, forthcoming.

[14] Stern, N. H. (1982), Optimum Taxation with Errors in Administration, Journal of Public Economics 17, 181-211.

[15] Stiglitz, J. E. (1982), Self-Selection and Pareto-Efficient Taxation, Journal of Public Economics 17, 213-240.

[16] Thaler, R. H., and C. R. Sunstein (2003), Libertarian Paternalism, American Economic Review 93, 175-179.

[17] Tobin, J. (1970), On Limiting the Domain of Inequality, Journal of Law and Economics 13, 263-277. 
WORKING PAPERS*

Editor: Nils Gottfries

2003:28 Per Pettersson-Lidbom and Matz Dahlberg, An Empirical Approach for Evaluating Soft Budget Contraints. $31 \mathrm{pp}$.

2003:29 Nils Gottfries, Booms and Busts in EMU. 34 pp.

2004:1 Iida Häkkinen, Working while enrolled in a university: Does it pay? 37 pp.

2004:2 Matz Dahlberg, Eva Mörk and Hanna Ågren, Do Politicians’ Preferences Correspond to those of the Voters? An Investigation of Political Representation. 34 pp.

2004:3 Lars Lindvall, Does Public Spending on Youths Affect Crime Rates? 40 pp.

2004:4 Thomas Aronsson and Sören Blomquist, Redistribution and Provision of Public Goods in an Economic Federation. 23 pp.

2004:5 Matias Eklöf and Daniel Hallberg, Private Alternatives and Early Retirement Programs. 30 pp.

2004:6 Bertil Holmlund, Sickness Absence and Search Unemployment. 38 pp.

2004:7 Magnus Lundin, Nils Gottfries and Tomas Lindström, Price and Investment Dynamics: An Empirical Analysis of Plant Level Data. 41 pp.

2004:8 Maria Vredin Johansson, Allocation and Ex Ante Cost Efficiency of a Swedish Subsidy for Environmental Sustainability: The Local Investment Program. 26 pp.

2004:9 Sören Blomquist and Vidar Christiansen, Taxation and Heterogeneous Preferences. $29 \mathrm{pp}$.

2004:10 Magnus Gustavsson, Changes in Educational Wage Premiums in Sweden: 1992-2001. 36 pp.

2004:11 Magnus Gustavsson, Trends in the Transitory Variance of Earnings: Evidence from Sweden 1960-1990 and a Comparison with the United States. 63 pp.

2004:12 Annika Alexius, Far Out on the Yield Curve. 41 pp.

2004:13 Pär Österholm, Estimating the Relationship between Age Structure and GDP in the OECD Using Panel Cointegration Methods. 32 pp.

2004:14 Per-Anders Edin and Magnus Gustavsson, Time Out of Work and Skill Depreciation. 29 pp.

\footnotetext{
* A list of papers in this series from earlier years will be sent on request by the department.
} 
2004:15 Sören Blomquist and Luca Micheletto, Redistribution, In-Kind Transfers and Matching Grants when the Federal Government Lacks Information on Local Costs. 34 pp.

2004:16 Iida Häkkinen, Do University Entrance Exams Predict Academic Achievement? 38 pp.

2004:17 Mikael Carlsson, Investment and Uncertainty: A Theory-Based Empirical Approach. 27 pp.

2004:18 N. Anders Klevmarken, Towards an Applicable True Cost-of-Living Index that Incorporates Housing. 8 pp.

2004:19 Matz Dahlberg and Karin Edmark, Is there a "Race-to-the-Bottom" in the Setting of Welfare Benefit Levels? Evidence from a Policy Intervention. $34 \mathrm{pp}$.

2004:20 Pär Holmberg, Unique Supply Function Equilibrium with Capacity Constraints. $31 \mathrm{pp}$.

2005:1 Mikael Bengtsson, Niclas Berggren and Henrik Jordahl, Trust and Growth in the 1990s - A Robustness Analysis. 30 pp.

2005:2 Niclas Berggren and Henrik Jordahl, Free to Trust? Economic Freedom and Social Capital. 31 pp.

2005:3 Matz Dahlberg and Eva Mörk, Public Employment and the Double Role of Bureaucrats. 26 pp.

2005:4 Matz Dahlberg and Douglas Lundin, Antidepressants and the Suicide Rate: Is There Really a Connection? $31 \mathrm{pp}$.

2005:5 Maria Vredin Johansson, Tobias Heldt and Per Johansson, Latent Variables in a Travel Mode Choice Model: Attitudinal and Behavioural Indicator Variables. $31 \mathrm{pp}$.

2005:6 Katarina Nordblom and Henry Ohlsson, Tax Avoidance and Intra-Family Transfers. 25 pp.

2005:7 Sören Blomquist and Luca Micheletto, Optimal Redistributive Taxation when Government's and Agents’ Preferences Differ. 22 pp.

See also working papers published by the Office of Labour Market Policy Evaluation http://www.ifau.se/

ISSN 0284-2904 